\title{
High-Mobility Group Box 1 expression predicts survival of patients after resection of adenocarcinoma of the ampulla of Vater
}

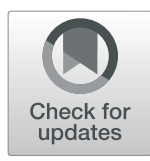

\author{
Takashi Murakami ${ }^{1}$, Ryusei Matsuyama ${ }^{1}$, Michio Ueda ${ }^{2}$, Yasuhisa Mochizuki ${ }^{3}$, Yuki Homma ${ }^{1,4}$, Kunio Kameda ${ }^{5}$, \\ Keiichi Yazawa ${ }^{6}$, Yusuke Izumisawa ${ }^{7}$, Tadao Fukushima $^{8}$, Nobuyuki Kamimukai ${ }^{9}$, Kenichi Yoshida $^{10}$, \\ Noriyuki Kamiya ${ }^{11}$, Robert M. Hoffman ${ }^{12,13}$ and Itaru Endo ${ }^{1 *}$
}

\begin{abstract}
Background: Expression of High-Mobility Group Box 1 (HMGB1), a multifunctional protein involved in DNA function as well as cell proliferation, inflammation, and the immune response, has been reported to be prognostic in several types of malignancies. However, the prognostic value of HMGB1 in ampullary cancer has not been studied.

Methods: Patients with adenocarcinoma of the ampulla of Vater who underwent R0 resection with pancreaticoduodenectomy between 2001 and 2011 were included in the present multi-institutional study. The degree of HMGB1 expression was examined in each resected specimen by immunohistochemical staining.

Results: A total of 101 patients were enrolled of which, 79 patients were eligible. High expression of HMGB1 was observed in 31 (39\%) patients. Blood loss, transfusion, tumor stage, nodal status, and HMGB1 expression were identified as predictors with univariate analysis. Multivariate analysis showed that transfusion, lymph-node metastasis, and high HMGB1 expression were independent predictors of poor overall survival. Subgroup analysis showed that high HMGB1 expression was predictive, especially in patients who did not receive adjuvant chemotherapy.
\end{abstract}

Conclusions: High HMGB1 expression is an independent predictor of poor prognosis in patients with adenocarcinoma of the ampulla of Vater not treated with adjuvant chemotherapy.

Keywords: HMGB1, Adenocarcinoma of the ampulla of Vater, Overall survival

\section{Introduction}

Ampullary cancer is a rare biliary tract cancer that accounts for $0.2 \%$ of digestive tract cancers in the USA [1]. The Japanese Society of Hepato-Biliary-Pancreatic Surgery reported a total of 13,192 bile duct cancer cases, including 2161 (16.4\%) ampullary cancer patients in 2016 [2]. Ampullary cancer patients are usually diagnosed at an early stage, with $30 \%$ of tumors localized in the mucosa or the sphincter of Oddi [2]. Therefore, more than half of the patients are treated with surgical resection, achieving relatively better long-term outcomes than other biliary tract cancers or pancreatic cancer [2, 3]. However, considering

\footnotetext{
* Correspondence: endoit@yokohama-cu.ac.jp

${ }^{1}$ Department of Gastroenterological Surgery, Graduate School of Medicine, Yokohama City University, 3-9, Fukuura, Kanazawa-ku, Yokohama 236-0004, Japan

Full list of author information is available at the end of the article
}

that lymph-node metastasis occurs even at an early stage of ampullary cancer, and the 5-year survival for patients with lymph-node metastasis is less than $30 \%$, improvement of patient outcome is still needed [2, 4]. Discovery of new predictive markers can provide new therapeutic targets that could result in further improvements in longterm outcome.

Expression of High-Mobility Group Box 1 (HMGB1), a multifunctional protein involved in DNA function as well as other cell functions, has been shown to be a prognostic factor in many cancers, such as esophageal cancer, gastric cancer, colorectal cancer, pancreatic cancer, and hepatocellular carcinoma [5]. However, the relationship between HMGB1 overexpression and survival in ampullary cancer has not yet been elucidated. Therefore, the present study was performed to determine the prognostic impact of HMGB1 in adenocarcinoma of the

(C) The Author(s). 2019 Open Access This article is distributed under the terms of the Creative Commons Attribution 4.0 International License (http://creativecommons.org/licenses/by/4.0/), which permits unrestricted use, distribution, and 
ampulla of Vater. Because of the rarity of the disease, clinicopathological data and pathological specimens from ampullary cancer patients were collected through a multi-institutional collaboration.

\section{Patients and methods}

\section{YCOG 1205, a multi-institutional study}

The Yokohama Clinical Oncology Group (YCOG) is a study group for investigating various surgical and oncological issues. The present multi-institutional, retrospective study was conducted as YCOG 1205 . Eleven institutions including the Department of Gastroenterological Surgery, Graduate School of Medicine, Yokohama City University; the Department of Surgery, Gastroenterological Center, Yokohama City University; the Department of Gastroenterological Surgery, Yokohama Municipal Citizen's Hospital; the Department of Surgery, Yokosuka Kyosai Hospital; the Department of Surgery, Yokosuka City Hospital; the Department of Surgery, Yokohama City Minato Red Cross Hospital; the Department of Gastroenterological Surgery, Fujisawa City Hospital; the Department of Surgery, Saiseikai Yokohama Nanbu Hospital; the Department of Surgery, Yokohama Hodogaya Central Hospital; the Department of Surgery, Saiseikai Wakakusa Hospital; and the Department of Surgery, Ito Municipal Hospital were involved. The study was conducted according to the Helsinki Declaration. The main institution, the Department of Gastroenterological Surgery, Graduate School of Medicine, Yokohama City University (IRB approval number: B120705037), and all other participating institutions approved the study protocol.

\section{Inclusion criteria}

Ampullary cancer was defined as a cancer derived from tissue surrounded by the Oddi muscle [6]. Patients with ampullary cancer treated with pancreaticoduodenectomy in YCOG were enrolled in the present study. Patients who met all of the following criteria were eligible for the present study: adenocarcinoma of the ampulla of Vater confirmed by histological examination; achievement of R0 resection by pancreaticoduodenectomy (PD), pylorus-preserving PD (PpPD), or subtotal stomach-preserving PD (SSPPD) between 2001 and 2011; and availability of tissue specimens. Pathologists in each institute reviewed the histological analysis. Clinicopathological data and paraffin-embedded resected tissue specimens or unstained slides from each participant were obtained and collected in the Department of Gastroenterological Surgery, Graduate School of Medicine, Yokohama City University.

Definition of lymph-node dissection for ampullary cancer The level of lymph-node dissection for ampullary cancer was classified into the following three categories according to the General Rules for Surgical and Pathological Studies on Cancer of the Biliary Tract, 5th edition [6]: D1, dissection of retro-pancreatic lymph-nodes; D2, dissection of pre-pancreatic lymph-nodes, mesenteric lymph-nodes (proximal portion of the superior mesenteric artery, inferior pancreaticoduodenal artery, middle colic artery, and jejunal artery), and lymph-nodes along the distal bile duct in addition to D1 dissection; and D3, dissection of paraaortic lymph-nodes and lymph-nodes around the celiac trunk, common hepatic artery, and hepato-duodenal ligament along with D2 dissection.

\section{Immunohistochemical staining}

Fresh tumor samples were fixed in formalin and embedded in paraffin before sectioning and staining. Tissue sections (4- $\mu \mathrm{m}$-thick) from the center of the tumors were deparaffinized in xylene and rehydrated in an ethanol series. Antigen retrieval was achieved by autoclaving in a citrate buffer (pH 6.0). Intrinsic peroxidase activity was quenched in a hydrogen peroxide phosphate-buffered saline for $30 \mathrm{~min}$ at room temperature. Then, bovine serum albumin $(10 \%)$ was added to block non-specific antibody binding. After blocking non-specific antibody binding, sections were incubated with the primary antibody, rabbit polyclonal anti-HMGB1 antibody (ab18256, Abcam, Cambridge, UK), at $4{ }^{\circ} \mathrm{C}$ overnight. The bound primary antibody was detected with an anti-rabbit secondary antibody. The labeled antigens were visualized with DAB. Sections were counterstained with hematoxylin.

\section{HMGB1 expression analysis}

The expression level of HMGB1 was evaluated by nuclear-staining intensity according to previously reported methods [7]. Four categories of staining were used: 1, no stain, 2-4, increasing intensity of brown stain (Fig. 1). Four categories of positivity were used, each with an increase of $25 \%$. Positivity scores were multiplied to obtain a histochemical score. High expression was defined as a score of greater than or equal to 8 , and low expression was defined as no more than 6 .

\section{Statistical analysis}

Statistical analyses were with SPSS statistics version 21.0 (IBM, New York City, NY, USA). The chi-squared test was used for statistical significance of categorical variables. The Mann-Whitney $U$ test was used for continuous variables. Kaplan-Meier analysis was used for survival and compared by the log-rank test. The Cox proportional hazards model was used for multivariate analysis on the outcome. Significant variables on univariate analysis were included in the multivariate analysis. A $P$ value $<0.05$ was considered significant. 

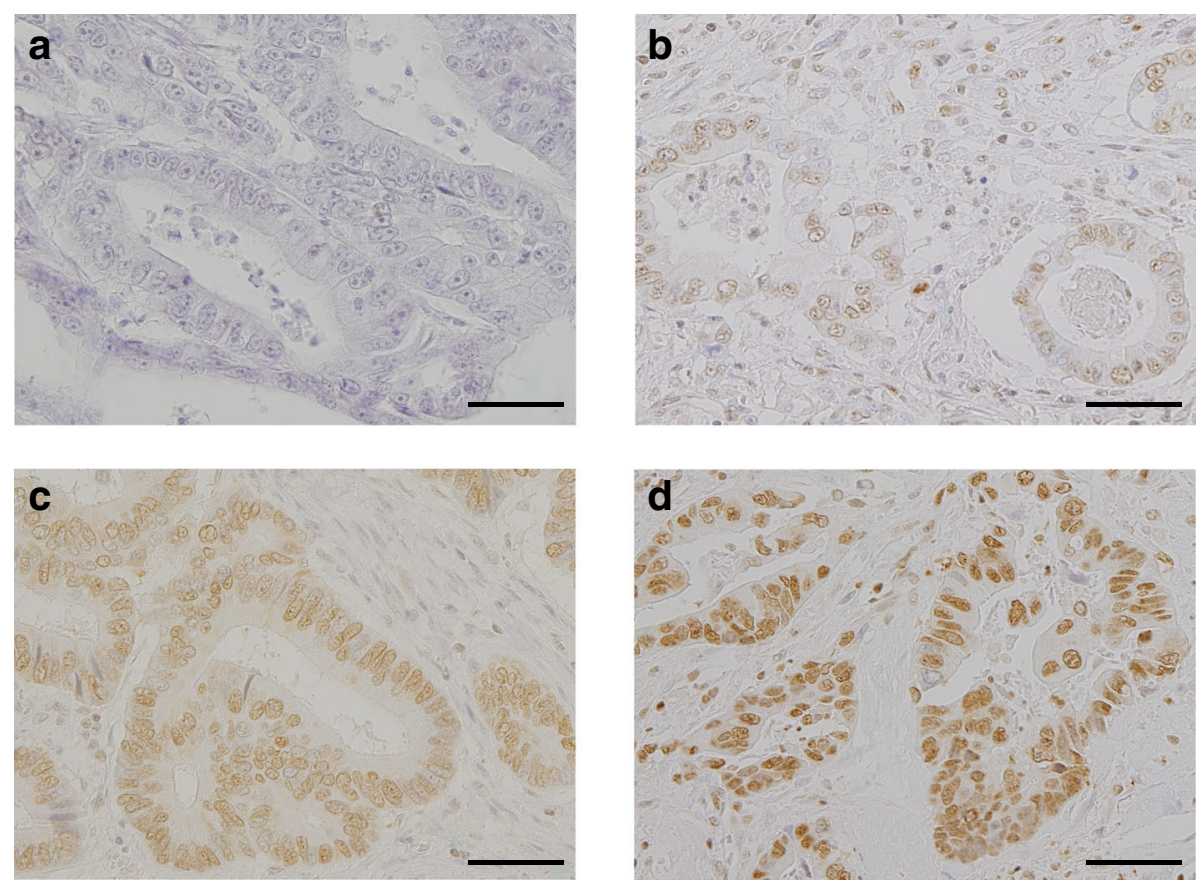

Fig. 1 Immunohistochemical staining images of HMGB1 expression in adenocarcinoma of the ampulla of Vater. Examples of HMGB1 expression in the nucleus of cancer cells. a No staining (intensity = 1). $\mathbf{b}$ Light brown staining (intensity =2). $\mathbf{c}$ Moderate brown staining (intensity $=3$ ). $\mathbf{d}$ Dark brown staining (intensity $=4$ ). Scale bars $=100 \mu \mathrm{m}$

\section{Results}

\section{Patient characteristics}

A total of 101 patients were enrolled, of which 79 patients were eligible for the present study using the criteria described above under the "Patients and methods" section. The patients' characteristics are summarized in Table 1. High expression of HMGB1 was confirmed in 31 (39\%) patients. Forty-five patients underwent conventional PD, and 31 underwent PpPD, while 3 patients were treated with SSPPD. Lymph-node dissection greater than D2 was performed on $55(70 \%)$ patients. Median operation time and blood loss were $466 \mathrm{~min}$ and $850 \mathrm{ml}$, respectively; 24\% of patients were transfused. Morbidity of greater than grade IIIa, according to the Clavien-Dindo classification, occurred in 35 (44\%) patients [8]. Of these cases, 20 had a grade B or $\mathrm{C}$ postoperative pancreatic fistula, defined by the International Study Group of Pancreatic Fistula classification [9]. According to the 8th Edition of the American Joint Committee on Cancer Staging Manual, there were 20 patients in stage IA, 18 in stage IB, 15 in stage IIA, 22 in stage IIIA, and 4 in stage IIIB [10]. Gemcitabine monotherapy was administered to 19 patients, and S-1 monotherapy was given to 7 patients. Three patients were treated with UFT, and intra-arterial chemotherapy using a 5-FU plus cisplatin regimen was administered to 2 patients, all as adjuvant chemotherapy. Most patients with lymph-node metastasis were given adjuvant chemotherapy (Table 2). No patients received radiation therapy.

\section{Relationship between HMGB1 expression and other clinicopathological variables}

Relationships between HMGB1 expression and other clinicopathological variables are shown in Table 3. Patients with high-expression HMGB1 underwent PD more frequently and showed a larger amount of blood loss than patients with low-expression. None of the tumor factors, including tumor diameter, tumor ulceration, histological type of adenocarcinoma, $\mathrm{T}$ state, and $\mathrm{N}$ stage, significantly correlated with HMGB1 expression level.

\section{Prognostic factors for patients with adenocarcinoma of the ampulla of Vater treated with Ro resection}

The 5-year overall survival rate and median survival time in the whole cohort were $58.1 \%$ and 113 months, respectively. Univariate analysis was performed to identify factors affecting overall survival (Table 4). Blood loss ( $\geq 800$ $\mathrm{ml}$ ), intraoperative transfusion, advanced $\mathrm{T}$ stage ( $\mathrm{T} 2$, T3a), lymph-node metastasis, and HMGB1 high expression were significantly associated with shorter overall survival. Multivariate analysis showed that intraoperative transfusion (hazard ratio [HR] 3.13; 95\% confidence interval $[\mathrm{CI}] 1.26-7.78 ; P=0.014)$, lymph-node metastasis (HR 7.43; 95\% CI 2.83-19.54; $P<0.001$ ), and HMGB1 high expression (HR 3.54; 95\% CI 1.37-9.16; $P=0.009$ ) were predictors of poor overall survival (Table 4). Kaplan-Meier analysis showed that the 5-year overall survival was significantly less in patients with high HMGB1 expression than 
Table 1 Patients' characteristics

\begin{tabular}{|c|}
\hline Variable \\
\hline Age \\
\hline Median (range) \\
\hline Sex \\
\hline Male \\
\hline Female \\
\hline Type of pancreatectomy \\
\hline PD \\
\hline PpPD \\
\hline SSPPD \\
\hline Node dissection \\
\hline D1 \\
\hline D2 \\
\hline D3 \\
\hline Operative time (min) \\
\hline Median (range) \\
\hline Blood loss (ml) \\
\hline Median (range) \\
\hline Transfusion \\
\hline Yes \\
\hline No \\
\hline Morbidity \\
\hline Clavien-Dindo grade IIla \\
\hline Pancreatic fistula Grade B, \\
\hline Tumor diameter (mm) \\
\hline Median (range) \\
\hline Tumor ulceration \\
\hline Yes \\
\hline No \\
\hline
\end{tabular}

Type of adenocarcinoma

Poorly differentiated

Moderately differentiated

Well differentiated

Papillary

Mucinous

T stage (AJCC 8th)

T1a

$\mathrm{T} 1 \mathrm{~b}$

$\mathrm{T} 2$

T3a

$N$ stage (AJCC 8th)

N0
N1
N2
Overall stage (AJCC 8th)

Table 1 Patients' characteristics (Continued)

\begin{tabular}{|c|c|}
\hline Variable & Patients $(n=79)$ \\
\hline $\mathrm{IA}$ & $20(25 \%)$ \\
\hline IB & $18(23 \%)$ \\
\hline$\| \mathrm{A}$ & 15 (19\%) \\
\hline$\| I I A$ & $22(28 \%)$ \\
\hline$\| \mathrm{IIB}$ & $4(5 \%)$ \\
\hline \multicolumn{2}{|l|}{ HMGB1 staining intensity } \\
\hline 1 (no staining) & $14(18 \%)$ \\
\hline 2 (light brown) & $34(43 \%)$ \\
\hline 3 (moderate brown) & $23(29 \%)$ \\
\hline 4 (brown or dark brown) & $8(10 \%)$ \\
\hline \multicolumn{2}{|l|}{ HMGB1 positive cells (\%) } \\
\hline $1(0-25 \%)$ & $32(41 \%)$ \\
\hline $2(26-50 \%)$ & $13(16 \%)$ \\
\hline $3(51-75 \%)$ & $10(13 \%)$ \\
\hline $4(76-100 \%)$ & $24(30 \%)$ \\
\hline \multicolumn{2}{|l|}{ HMGB1 expression } \\
\hline High & 31 (39\%) \\
\hline Low & $48(61 \%)$ \\
\hline \multicolumn{2}{|l|}{ Adjuvant chemotherapy } \\
\hline Yes & $28(35 \%)$ \\
\hline Gem & $19(24 \%)$ \\
\hline S-1 & $7(9 \%)$ \\
\hline Others & $5(6 \%)$ \\
\hline No & $51(65 \%)$ \\
\hline
\end{tabular}

$P D$ pancreaticoduodenectomy, $P p P D$ pylorus-preserving pancreaticoduodenectomy, SSPPD subtotal stomach-preserving pancreaticoduodenectomy, AJCC American Joint Committee on Cancer, HMGB1 High-Mobility Group Box 1, Gem gemcitabine

$22(28 \%)$

$57(72 \%)$

$11(14 \%)$

$22(28 \%)$

$33(42 \%)$

$12(15 \%)$

$1(1 \%)$

$21(27 \%)$

$16(20 \%)$

$15(19 \%)$

$27(34 \%)$

$53(67 \%)$

$22(28 \%)$

$4(5 \%)$

in those with low HMGB1 expression (36.1\% and $72.4 \%$, respectively; $P=0.025$; Fig. 2 ).

HMGB1 expression was significantly prognostic only in patients who did not receive adjuvant chemotherapy High expression of HMGB1 was a good predictor of survival for patients without adjuvant chemotherapy (5-year overall survival with high and low HMGB1 expression: $36.8 \%$ and $71.8 \%$, respectively; $P=0.019$; Fig. $3 \mathrm{a}$ ), but not for patients who received adjuvant chemotherapy (5-year overall survival in high and low HMGB1 expression: $32.8 \%$ and $57.0 \%$, respectively; $P=0.63$; Fig. $3 b$ ).

Table 2 Relationship between N stage and adjuvant chemotherapy

\begin{tabular}{llll}
\hline & $\begin{array}{l}\text { Adjuvant chemotherapy } \\
(-)\end{array}$ & $\begin{array}{l}\text { Adjuvant chemotherapy } \\
(+)\end{array}$ & $\begin{array}{l}P \\
\text { value }\end{array}$ \\
\hline N0 & 40 & 13 & 0.004 \\
N1, & 11 & 15 & \\
N2 & & & \\
\hline
\end{tabular}


Table 3 Relationships between HMGB1 expression and clinicopathological factors

\begin{tabular}{|c|c|c|c|}
\hline Variable & $\begin{array}{l}\text { HMGB1 high } \\
(n=31)\end{array}$ & $\begin{array}{l}\text { HMGB1 low } \\
(n=48)\end{array}$ & $\begin{array}{l}P \\
\text { value }\end{array}$ \\
\hline \multicolumn{4}{|l|}{ Age } \\
\hline Median (range) & $68(46-83)$ & $66(42-83)$ & 0.42 \\
\hline \multicolumn{4}{|l|}{ Sex } \\
\hline Male & $11(35 \%)$ & $24(50 \%)$ & 0.21 \\
\hline Female & $20(65 \%)$ & $24(50 \%)$ & \\
\hline \multicolumn{4}{|c|}{ Type of pancreatectomy } \\
\hline PD & $23(74 \%)$ & $22(46 \%)$ & 0.013 \\
\hline PpPD, SSPPD & $8(26 \%)$ & $26(54 \%)$ & \\
\hline \multicolumn{4}{|l|}{ Node dissection } \\
\hline D1 & $12(39 \%)$ & $12(25 \%)$ & 0.20 \\
\hline D2, D3 & $19(61 \%)$ & $36(75 \%)$ & \\
\hline \multicolumn{4}{|l|}{ Operative time (min) } \\
\hline Median (range) & $490(308-716)$ & $451(0-856)$ & 0.3 \\
\hline \multicolumn{4}{|l|}{ Blood loss (ml) } \\
\hline Median (range) & 949 (150-3696) & $722(100-3020)$ & 0.025 \\
\hline \multicolumn{4}{|l|}{ Transfusion } \\
\hline Yes & $8(26 \%)$ & $11(23 \%)$ & 0.77 \\
\hline No & $23(74 \%)$ & $37(77 \%)$ & \\
\hline \multicolumn{4}{|l|}{ Morbidity (grade IIIa) } \\
\hline Yes & $13(42 \%)$ & $22(46 \%)$ & 0.73 \\
\hline No & $18(58 \%)$ & $26(54 \%)$ & \\
\hline \multicolumn{4}{|l|}{ Tumor diameter (mm) } \\
\hline Median (range) & $20(8-35)$ & $20(8-65)$ & 0.074 \\
\hline \multicolumn{4}{|l|}{ Tumor ulceration } \\
\hline Yes & $9(29 \%)$ & $13(27 \%)$ & 0.85 \\
\hline No & $22(71 \%)$ & $35(73 \%)$ & \\
\hline \multicolumn{4}{|c|}{ Type of adenocarcinoma } \\
\hline $\begin{array}{l}\text { Moderate or poor } \\
\text { differentiated }\end{array}$ & $12(39 \%)$ & $21(44 \%)$ & 0.66 \\
\hline Other types & $19(61 \%)$ & $27(56 \%)$ & \\
\hline \multicolumn{4}{|l|}{ T stage (AJCC 8th) } \\
\hline Тза & $9(29 \%)$ & $18(38 \%)$ & 0.44 \\
\hline $\mathrm{T} 1 \mathrm{a}, \mathrm{T} 1 \mathrm{~b}, \mathrm{~T} 2$ & $22(71 \%)$ & $30(62 \%)$ & \\
\hline \multicolumn{4}{|l|}{ N stage (AJCC 8th) } \\
\hline $\mathrm{N} 1, \mathrm{~N} 2$ & $12(39 \%)$ & $14(29 \%)$ & 0.38 \\
\hline NO & 19 (61\%) & $34(71 \%)$ & \\
\hline \multicolumn{4}{|c|}{ Overall stage (AJCC 8th) } \\
\hline$\|A\| A,, \| B$ & $17(55 \%)$ & $24(50 \%)$ & 0.67 \\
\hline $\mid A, I B$ & $14(45 \%)$ & $24(50 \%)$ & \\
\hline \multicolumn{4}{|c|}{ Adjuvant chemotherapy } \\
\hline$(-)$ & $20(65 \%)$ & $31(65 \%)$ & 1.00 \\
\hline$(+)$ & $11(35 \%)$ & $17(35 \%)$ & \\
\hline
\end{tabular}

\section{Discussion}

The only known treatment to achieve cure for ampullary cancer is surgical resection. Since 4.6 to $9 \%$ of T1 ampullary cancer cases have lymph-node metastasis, the standard treatment method in Japan is pancreaticoduodenectomy with lymph-node dissection [2, 4, 11]. It has been shown that $\mathrm{T}$ stage, lymph-node metastasis, residual cancer cells, and intraoperative transfusion are predictors of poor prognosis in ampullary cancer [12-16]. Moreover, the pancreatobiliary type on histological subtyping, which was first reported by Kimura et al., has also been demonstrated to be associated with survival $[14,17]$. Fluorouracil-based adjuvant chemoradiotherapy may prolong survival of ampullary cancer patients following pancreaticoduodenectomy, but the evidence is limited [18].

HMGB1, a non-histone DNA-binding protein first reported in the calf thymus in 1973, is present in most mammalian cells $[19,20]$. Wang et al. showed that HMGB1 was involved in inflammatory responses [21]. Intranuclear HMGB1 participates in several DNA functions, including DNA chaperone, DNA repair, transcription, maintenance of telomeres, and genome stability. Moreover, previous studies reported that HMGB1 enhances the functions of key immune suppressor cells such as myeloid-derived suppressor cells and regulatory $\mathrm{T}$ cells, inhibiting anti-tumor immune responses [22, 23]. Furthermore, HMGB1 expression was inversely associated with $\mathrm{CD}^{2} 5 \mathrm{RO}^{+} \mathrm{T}$ cell infiltration in colon cancer [24]. Thus, HMGB1 affects anti-tumor immune responses, but further investigations are necessary to better understand the role of HMGB1 in anti-tumor immunity.

Importantly, recent studies have found that HMGB1 expression is associated with tumorigenesis and tumor progression [25, 26]. HMGB1 appears to play a particular role in apoptosis inhibition, cell proliferation, angiogenesis, invasion, and metastasis in many malignancies [26]. Wu et al. reviewed the impact of HMGB1 overexpression on patient survival in several cancers [5]. Overexpression of HMGB1 was significantly correlated with poorer overall survival in esophageal cancer, gastric cancer, colorectal cancer, pancreatic cancer, hepatocellular carcinoma, nasopharyngeal cancer, head and neck cancer, bladder cancer, cervical cancer, and pleural mesothelioma. Moreover, there are some reports of HMGB1 in biliary tract cancers. RAGE, a receptor binding to HMGB1, was reportedly associated with invasion capacity in a study using bile duct-cancer cell lines [27]. Xu et al. investigated HMGB1 expression in intrahepatic cholangiocarcinoma, concluding that HMGB1 overexpression was significantly correlated with worse survival [28]. The level of HMGB1 expression was reported to be associated with lymph-node metastasis and advanced TNM stage in esophageal cancer, gastric cancer, colorectal cancer, head and neck cancer, and cervical cancer [29-33]. Moreover, HMGB1 
Table 4 Univariate and multivariate analyses of predictors of overall survival

\begin{tabular}{|c|c|c|c|c|c|c|}
\hline \multirow{2}{*}{$\begin{array}{l}\text { Univariate analysis } \\
\text { Variable }\end{array}$} & \multirow[b]{2}{*}{$H R$} & \multirow[b]{2}{*}{$95 \% \mathrm{Cl}$} & \multirow[b]{2}{*}{$P$ value } & \multicolumn{2}{|c|}{ Multivariate analysis } & \multirow[b]{2}{*}{$P$ value } \\
\hline & & & & $\mathrm{HR}$ & $95 \% \mathrm{Cl}$ & \\
\hline Age $(60 \leq)$ & 0.62 & $0.26-1.50$ & 0.29 & - & - & - \\
\hline Sex (male) & 1.40 & $0.61-3.22$ & 0.42 & - & - & - \\
\hline Type of pancreatectomy (PD) & 1.43 & $0.63-3.22$ & 0.39 & - & - & - \\
\hline Node dissection (D1) & 1.87 & $0.83-4.23$ & 0.19 & - & - & - \\
\hline Operative time (480 $\min \leq$ ) & 0.97 & $0.42-2.20$ & 0.93 & - & - & - \\
\hline Blood loss (800 ml $\leq$ ) & 3.46 & $1.28-9.34$ & 0.014 & 1.88 & $0.60-5.91$ & 0.28 \\
\hline Transfusion (yes) & 3.21 & $1.44-7.17$ & 0.004 & 3.13 & $1.26-7.78$ & 0.014 \\
\hline Morbidity (grade IIla) & 0.98 & $0.44-2.19$ & 0.96 & - & - & - \\
\hline Tumor diameter (20 mm $\leq$ ) & 1.12 & $0.47-2.65$ & 0.80 & - & - & - \\
\hline Histological type (moderate or poor) & 1.93 & $0.86-4.32$ & 0.11 & - & - & - \\
\hline T stage (T2, T3a) & 2.57 & $1.05-6.25$ & 0.038 & 1.31 & $0.47-3.63$ & 0.60 \\
\hline $\mathrm{N}$ stage (N1, N2) & 9.12 & $3.53-23.57$ & $<0.001$ & 7.43 & $2.83-19.54$ & $<0.001$ \\
\hline HMGB1 expression (High) & 2.48 & $1.09-5.66$ & 0.030 & 3.54 & $1.37-9.16$ & 0.009 \\
\hline Adjuvant chemotherapy (-) & 0.70 & $0.30-1.64$ & 0.42 & - & - & - \\
\hline
\end{tabular}

expression was positively correlated with lymphatic-vessel density in esophageal cancer and intrahepatic cholangiocarcinoma [28, 29]. These results suggest possible reasons why HMGB1 overexpression may contribute to poorer patient survival.

The present study is the first to examine the association of HMGB1 expression and ampullary cancer. Our study demonstrated that high HMGB1 expression was significantly associated with shorter survival for patients with adenocarcinoma of the ampulla of Vater following R0 resection. HMGB1 was predictive for patients only without adjuvant chemotherapy. Adjuvant chemotherapy for patients with high HMGB1 expression, as well as patients with lymph-node metastasis, may be effective for some patients. Recently, there have been reports on novel HMGB1-targeted therapy in preclinical models. In a mouse model, anti-HMGB1 antibody therapy was reported to reduce colorectal cancer liver metastasis

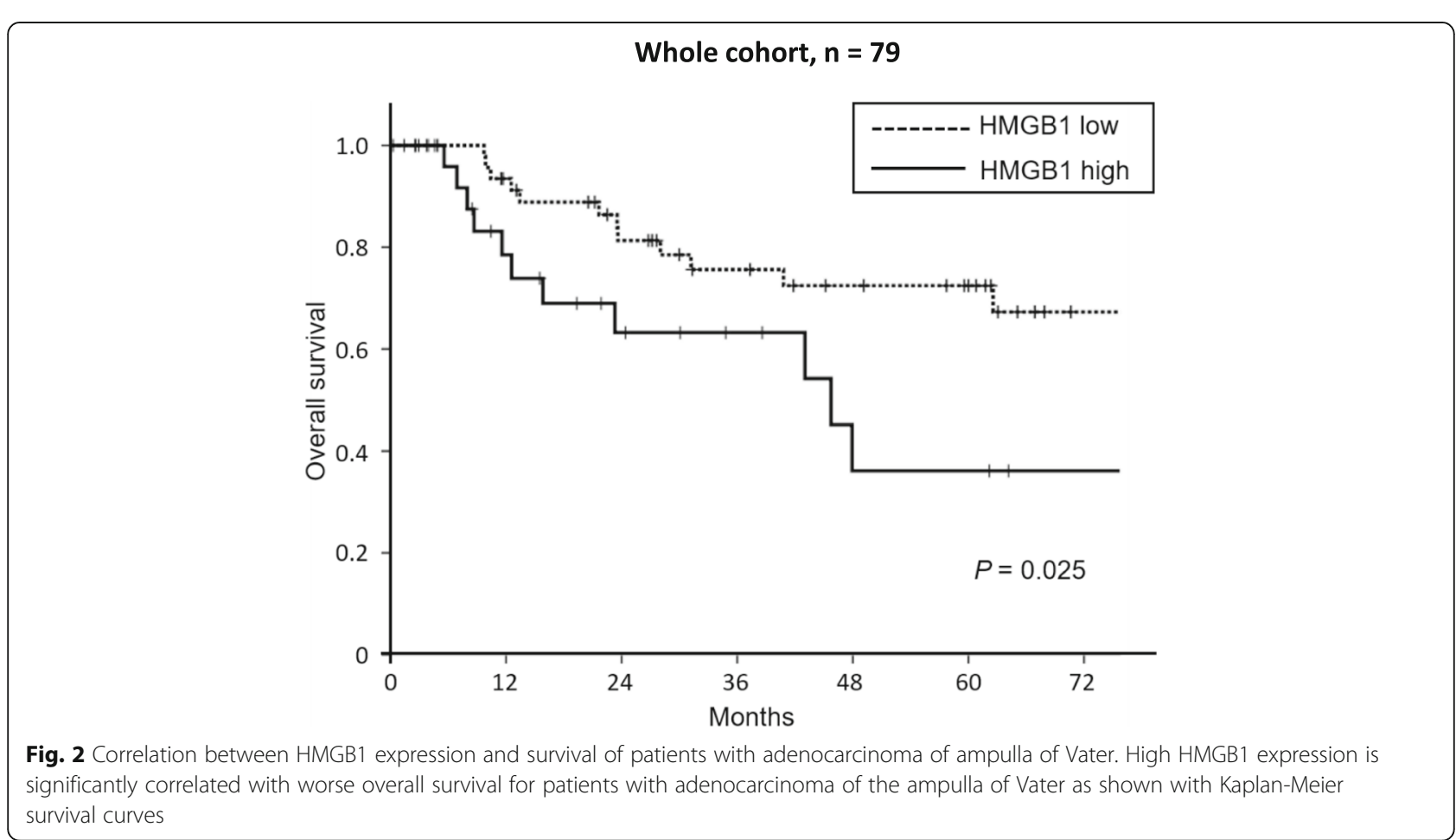




\section{a Adjuvant chemotherapy (-), $\mathrm{n}=\mathbf{5 1}$}

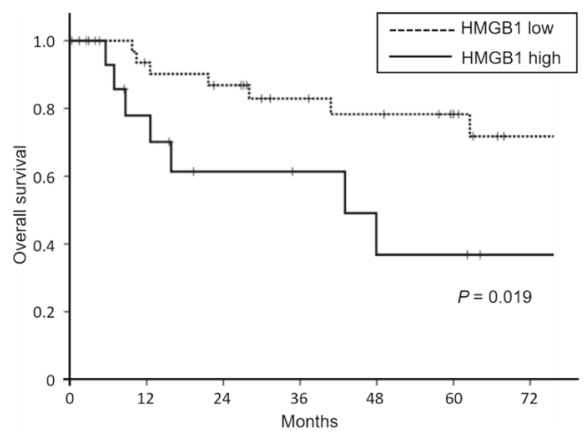

b Adjuvant chemotherapy (+), $n=28$

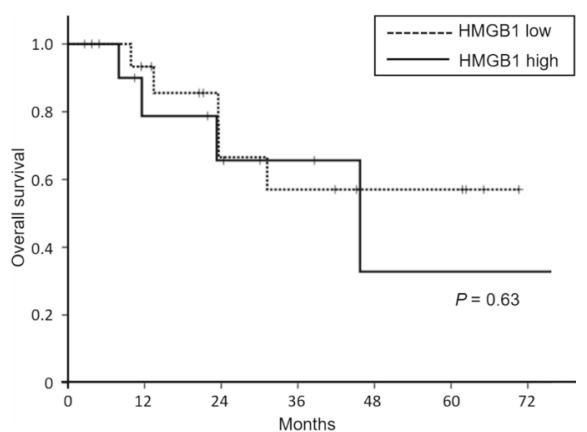

Fig. 3 a, b Lack of correlation between HMGB1 expression and survival of patients with adenocarcinoma of ampulla of Vater treated with adjuvant chemotherapy. High HMGB1 expression was not significantly associated with poorer survival of patients treated with adjuvant chemotherapy

derived from a cell line expressing the highest level of HMGB1 [34]. Similarly, a study using mouse models showed that HMGB1-RAGE-signaling blockade suppressed tumor growth in which both RAGE and HMGB1 were expressed [35]. Based on these results, HMGB1-targeted therapy for ampullary cancer with HMGB1 overexpression is promising. Our results suggest a general phenomenon that has to be further studied.

There are several limitations in this study. First, the total number of patients was not high, despite it being a multi-institutional study. Second, the patients underwent different adjuvant chemotherapy regimens. Finally, the detailed molecular biological mechanisms of HMGB1 examined in the present study were not studied. Even after taking these limitations into consideration, however, the results of the present study suggests a new biomarker for survival, as well as a potential treatment target for adenocarcinoma of the ampulla of Vater. We have not studied the expression of HMGB1 as a function of the histologic subtype and plan to do in future studies.

\section{Conclusions}

The present study suggests that HMGB1 is a prognostic factor and potential biomarker for survival in patients not treated with adjuvant chemotherapy with adenocarcinoma of the ampulla of Vater not treated with adjuvant chemotherapy.

\section{Abbreviations \\ HMGB1: High-Mobility Group Box 1; PD: Pancreaticoduodenectomy; PpPD: Pylorus-preserving pancreaticoduodenectomy; SSPPD: Subtotal stomach-preserving pancreaticoduodenectomy; YCOG: Yokohama Clinical Oncology Group}

\section{Acknowledgements}

The authors are deeply grateful to Harumi Sakurada, Drs. Yusaku Tanaka, and Kentaro Miyake for their skillful laboratory work. They are also grateful to Drs. Keiichi Yazawa, Koki Goto, Daisuke Kawaguchi, Hiroki Takahashi, Hiroki Ohya, and Yoshie Fujiwara for collecting patient information.

\section{Authors' contributions}

RM contributed to the conceptualization. TM, MU, YM, YH, KK, KY, YI, TF, NK, KY, and NK contributed to the data collection. TM, RM, and IE contributed to the analysis and interpretation. TM, RM, and YH contributed to the interpretation of HMGB1 expression in the immunohistochemistry slides. TM contributed to the draft preparation. $\mathrm{RM}, \mathrm{RMH}$, and IE did the review and editing. IE and RMH supervised. All authors read and approved the final manuscript.

\section{Funding}

Not applicable.

\section{Availability of data and materials}

The datasets used and/or analyzed during the current study are available from the corresponding author on reasonable request.

\section{Ethics approval and consent to participate}

The study was conducted according to the Helsinki Declaration. The main institution, the Department of Gastroenterological Surgery, Graduate School of Medicine, Yokohama City University (IRB approval number: B120705037), and all other participating institutions approved the study protocol.

Consent for publication

Not applicable.

\section{Competing interests}

The authors declare that they have no competing interests.

\section{Author details}

'Department of Gastroenterological Surgery, Graduate School of Medicine, Yokohama City University, 3-9, Fukuura, Kanazawa-ku, Yokohama 236-0004, Japan. ${ }^{2}$ Department of Surgery, Gastroenterological Center, Yokohama City University, Yokohama, Japan. ${ }^{3}$ Department of Gastroenterological Surgery, Yokohama Municipal Citizen's Hospital, Yokohama, Japan. ${ }^{4}$ Department of Surgery, Yokosuka Kyosai Hospital, Yokosuka, Japan. ${ }^{5}$ Department of Surgery, Yokosuka City Hospital, Yokosuka, Japan. ${ }^{6}$ Department of Surgery, Yokohama

City Minato Red Cross Hospital, Yokohama, Japan. ${ }^{7}$ Department of Gastroenterological Surgery, Fujisawa City Hospital, Fujisawa, Japan. ${ }^{8}$ Department of Surgery, Saiseikai Yokohama Nanbu Hospital, Yokohama, Japan. ${ }^{9}$ Department of Surgery, Yokohama Hodogaya Central Hospital, Yokohama, Japan. ${ }^{10}$ Department of Surgery, Saiseikai Wakakusa Hospital, Yokohama, Japan. "'Department of Surgery, Ito Municipal Hospital, Ito, Japan. ${ }^{12}$ Department of Surgery, University of California, San Diego, California, USA.

${ }^{13}$ AntiCancer, Inc., San Diego, California, USA. 
Received: 3 March 2019 Accepted: 23 July 2019

Published online: 09 August 2019

\section{References}

1. Ahn DH, Bekaii-Saab T. Ampullary cancer: an overview. Am Soc Clin Oncol Educ Book. 2014:112-5.

2. Ishihara S, Horiguchi A, Miyakawa S, Endo I, Miyazaki M, Takada T. Biliary tract cancer registry in Japan from 2008 to 2013. J Hepatobiliary Pancreat Sci. 2016;23(3):149-57.

3. Riall TS, Cameron JL, Lillemoe KD, Winter JM, Campbell KA, Hruban RH, et al. Resected periampullary adenocarcinoma: 5-year survivors and their 6- to 10year follow-up. Surgery. 2006;140(5):764-72.

4. Yoon Y-S, Kim S-W, Park SJ, Lee HS, Jang J-Y, Choi MG, et al. Clinicopathologic analysis of early ampullary cancers with a focus on the feasibility of ampullectomy. Ann Surg. 2005;242(1):92-100.

5. Wu T, Zhang W, Yang G, Li H, Chen Q, Song R, et al. HMGB1 overexpression as a prognostic factor for survival in cancer: a meta-analysis and systematic review. Oncotarget. 2016;7(31):50417-27.

6. Japanese Society of Biliary Surgery. General Rules for Surgical and Pathological Studies on Cancer of the Biliary Tract, the 5th edition. 2003.

7. Zhang $Q B$, Jia $Q A$, Wang $H$, Hu CX, Sun D, Jiang RD, et al. High-mobility group protein box 1 expression correlates with peritumoral macrophage infiltration and unfavorable prognosis in patients with hepatocellular carcinoma and cirrhosis. BMC Cancer. 2016;16(1):880.

8. Clavien PA, Barkun J, de Oliveira ML, Vauthey JN, Dindo D, Schulick RD, et al. The Clavien-Dindo classification of surgical complications: five-year experience. Ann Surg. 2009;250(2):187-96.

9. Bassi C, Dervenis C, Butturini G, Fingerhut A, Yeo C, Izbicki J, et al. Postoperative pancreatic fistula: an international study group (ISGPF) definition. Surgery. 2005;138(1):8-13.

10. Chun YS, Pawlik TM, Vauthey JN. 8th Edition of the AJCC Cancer Staging Manual: pancreas and hepatobiliary cancers. Ann Surg Oncol. 2018;25(4):845-7.

11. Miyazaki M, Yoshitomi H, Miyakawa S, Uesaka K, Unno M, Endo I, et al. Clinical practice guidelines for the management of biliary tract cancers 2015: the 2nd English edition. J Hepatobiliary Pancreat Sci. 2015;22(4):249-73.

12. Chan C, Herrera MF, de la Garza L, Quintanilla-Martinez L, Vargas-Vorackova $F$, Richaud-Patin $Y$, et al. Clinical behavior and prognostic factors of periampullary adenocarcinoma. Ann Surg. 1995;222(5):632-7.

13. Chen SC, Shyr YM, Chou SC, Wang SE. The role of lymph nodes in predicting the prognosis of ampullary carcinoma after curative resection. World J Surg Oncol. 2015;13:224.

14. Robert PE, Leux C, Ouaissi M, Miguet M, Paye F, Merdrignac A, et al. Predictors of long-term survival following resection for ampullary carcinoma: a large retrospective French multicentric study. Pancreas. 2014;43(5):692-7.

15. Tol JA, Brosens LA, van Dieren S, van Gulik TM, Busch OR, Besselink MG, et al. Impact of lymph node ratio on survival in patients with pancreatic and periampullary cancer. Br J Surg. 2015;102(3):237-45

16. Klein F, Jacob D, Bahra M, Pelzer U, Puhl G, Krannich A, et al. Prognostic factors for long-term survival in patients with ampullary carcinoma: the results of a 15-year observation period after pancreaticoduodenectomy. HPB Surg. 2014;2014:970234.

17. Kimura W, Futakawa N, Yamagata S, Wada Y, Kuroda A, Muto T, et al. Different clinicopathologic findings in two histologic types of carcinoma of papilla of Vater. Jpn J Cancer Res. 1994;85(2):161-6.

18. Narang AK, Miller RC, Hsu CC, Bhatia S, Pawlik TM, Laheru D, et al. Evaluation of adjuvant chemoradiation therapy for ampullary adenocarcinoma: the Johns Hopkins Hospital-Mayo Clinic collaborative study. Radiat Oncol. 2011;6:126

19. Goodwin $\mathrm{GH}$, Johns EW. Isolation and characterisation of two calf-thymus chromatin non-histone proteins with high contents of acidic and basic amino acids. Eur J Biochem. 1973;40(1):215-9.

20. He SJ, Cheng J, Feng X, Yu Y, Tian L, Huang Q. The dual role and therapeutic potential of high-mobility group box 1 in cancer. Oncotarget. 2017;8(38):64534-50.

21. Wang $\mathrm{H}$, Bloom $\mathrm{O}$, Zhang $M$, Vishnubhakat JM, Ombrellino $M$, Che J, et al. HMG-1 as a late mediator of endotoxin lethality in mice. Science. 1999;285(5425):248-51.

22. Parker KH, Horn LA, Ostrand-Rosenberg S. High-mobility group box protein 1 promotes the survival of myeloid-derived suppressor cells by inducing autophagy. J Leukoc Biol. 2016;100(3):463-70.
23. Wild CA, Brandau S, Lotfi R, Mattheis S, Gu X, Lang S, et al. HMGB1 is overexpressed in tumor cells and promotes activity of regulatory $T$ cells in patients with head and neck cancer. Oral Oncol. 2012;48(5):409-16.

24. Peng RQ, Wu XJ, Ding Y, Li CY, Yu XJ, Zhang X, et al. Co-expression of nuclear and cytoplasmic HMGB1 is inversely associated with infiltration of CD45RO+ T cells and prognosis in patients with stage IIIB colon cancer. BMC Cancer. 2010;10:496.

25. Ellerman JE, Brown CK, de Vera M, Zeh HJ, Billiar T, Rubartelli A, et al. Masquerader: high mobility group box-1 and cancer. Clin Cancer Res. 2007;13(10):2836-48.

26. Tang D, Kang R, Zeh HJ 3rd, Lotze MT. High-mobility group box 1 and cancer. Biochim Biophys Acta. 2010;1799(1-2):131-40.

27. Hirata K, Takada M, Suzuki Y, Kuroda Y. Expression of receptor for advanced glycation end products (RAGE) in human biliary cancer cells. Hepatogastroenterology. 2003;50(53):1205-7.

28. Xu YF, Ge FJ, Han B, Yang XQ, Su H, Zhao AC, et al. High-mobility group box 1 expression and lymph node metastasis in intrahepatic cholangiocarcinoma. World J Gastroenterol. 2015;21(11):3256-65.

29. Chuangui $C$, Peng T, Zhentao $Y$. The expression of high mobility group box 1 is associated with lymph node metastasis and poor prognosis in esophageal squamous cell carcinoma. Pathol Oncol Res. 2012;18(4):1021-7.

30. He W, Tang B, Yang D, Li Y, Song W, Cheang T, et al. Double-positive expression of high-mobility group box 1 and vascular endothelial growth factor $\mathrm{C}$ indicates a poorer prognosis in gastric cancer patients. World J Surg Oncol. 2013;11:161.

31. Zhang $X, Y u$ J, Li M, Zhu H, Sun X, Kong L. The association of HMGB1 expression with clinicopathological significance and prognosis in Asian patients with colorectal carcinoma: a meta-analysis and literature review. Onco Targets Ther. 2016;9:4901-11.

32. Nguyen A, Bhavsar S, Riley E, Caponetti G, Agrawal D. Clinical value of high mobility group box 1 and the receptor for advanced glycation endproducts in head and neck cancer: a systematic review. Int Arch Otorhinolaryngol. 2016;20(4):382-9.

33. Cheng H, Wang W, Zhang Y, Zhang B, Cheng J, Teng P, et al. Expression levels and clinical significance of hepsin and HMGB1 proteins in cervical carcinoma. Oncol Lett. 2017;14(1):159-64.

34. Luo Y, Ohmori H, Fujii K, Moriwaka Y, Sasahira T, Kurihara M, et al. HMGB1 attenuates anti-metastatic defence of the liver in colorectal cancer. Eur J Cancer. 2010:46(4):791-9.

35. Taguchi A, Blood DC, del Toro G, Canet A, Lee DC, Qu W, et al. Blockade of RAGE-amphoterin signalling suppresses tumour growth and metastases. Nature. 2000:405(6784):354-60.

\section{Publisher's Note}

Springer Nature remains neutral with regard to jurisdictional claims in published maps and institutional affiliations.

\section{Ready to submit your research? Choose BMC and benefit from:}

- fast, convenient online submission

- thorough peer review by experienced researchers in your field

- rapid publication on acceptance

- support for research data, including large and complex data types

- gold Open Access which fosters wider collaboration and increased citations

- maximum visibility for your research: over $100 \mathrm{M}$ website views per year

At BMC, research is always in progress.

Learn more biomedcentral.com/submissions 